\section{ON THE SPECTROSCOPE AND ITS APPLICATIONS VIII.}

T TOLD you I had something more to say about the spectrum of blood, and this is not only an instance of the way in which the spectrum helps us in several important questions that, at first sight, do not seem at all connected with cach other, but it shows the enormous power of research that is open to us. The colouring matter of blood, for instance, is found, like that of indigo, to exist in two perfectly different states, which give two perfectly different spectra. The colouring matter of blood is indeed capable of existing in two states of oxidation, which are distinguishable by a difference in colour, and also in their action on the spectrum. They may be made to pass one into the other by suitable oxidising and reducing agents; they have been named by Professor Stokes, their discoverer, red and purple cruo. rine. Previous to the introduction of spectrum analysis, red and purple cruorine were perfectly unknown. Further, if by means of a spectrum microscope, such as I have already described, a blood-stain is examined, Mr. Sorby asserts that the thousandth part of a grain of blood, - that is to say, a blood-spot so small that it only contains $\frac{1}{1000}$ of a grain, is perfectly easy of detection by means of this new method, and he has shown that its presence may be easily proved in stains that have been kept for a long time, and recognised even after a period of fifty years.

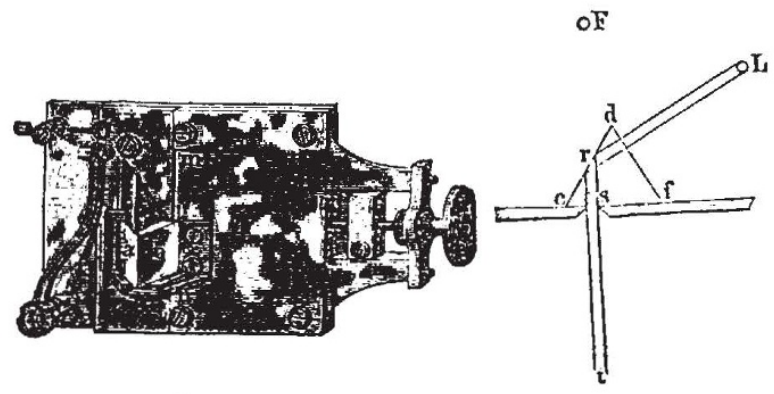

Fig. $4^{\text {r. }}$

Fic. 47.

Fig. 46.-Steinhcil's slit; showing reflectirg prism. Fig. 47.-Path of light through reflecting prism and into the slit.

He has also shown how it may be detected under the most unfavourable conditions, provided that a trace of hæematin has escaped decomposition or removal; he has, in fact, successfully applied this method in several important criminal cases.

Another very interesting fact is, that when blood contains very small quantities of carbonic oxide gas in solution, it exhibits a very curious series of absorption bands. This fact is of considerable value in toxicological research, for in cases of poisoning by the so-called charcoal fumes, where, as is well known, the poisonous action is due to the formation of carbonic oxide, it can be readily detected by the peculiar. bands which the blood under these circumstances exhibits.

Mr. Sorby has also applied the spectrum microscope to the study of blow-pipe beads, and has shown that in some cases as small a quantity as $\frac{x}{1000}$ th of a grain of some substances can be thus recognised, even when mixed with other coloured bodies, which would interfere with the usual reactions dependent on colour alone.

In the case of radiation, as you know, we are able to determine the existence of new elements altogether. This is produced to a certain extent, as in the above case, in the absorption spsctrum. Let me give you another practical application of this principle. Dr. Thudichum, as a result of researches made for the Medical Department of the Privy Council, has communicated to the Royal Socicty a paper in which he narrates the result of his inquiries on the yellow organic substances contained in animals and plants; and at the present moment it is impossible to say what important practical results may be expected as we come to know more about these substances, especially in the matter of dyes, which I am sure is a thing that will commend itself to you.

Again, Mr. Sorby; in a communication to the Microscopical Society, brings the matter still nearer home. He shows us that, in the case of wines, he can, by means of the absorption bands, determine the very year even of vintage, and this, you will see at once, is a matter of very great importance. Let me read you an extract from one of Mr. Sorby's reports. He says :- "The difference for each year is at first so considerable that wines of different vintages could easily be distinguished; but after about six years, the difference is so small that it would be difficult or impossible to determine the age to within a single year. After twenty years, a difference of even ten years

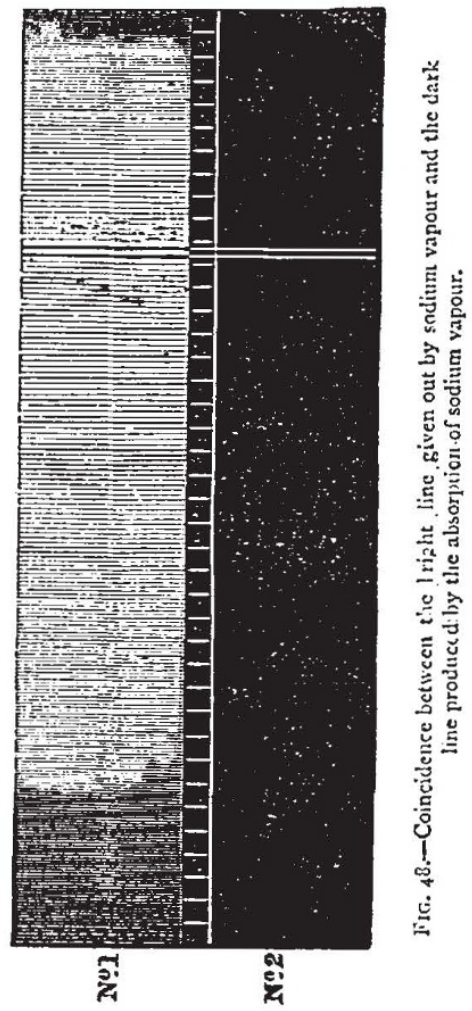

does not show any striking contrast, and the age could not, therefore, be determined to nearer than ten years by this process. However, up to six years I think it quite possible to determine the age to within a single year. I took specimens of various ports from the casks, of different ages up to six or seven years, and labelled them in such a manner that I did not know the age of any, but could ascertain it afterwards by reference. I then made the experiments with great care, and found that, by proper attention to the details described above, I could correctly determine the year of vintage of each particular specimen." (Chemical News, December I7, 1869, p. 295.)

We have, in fact, a definite method of analysis of animal and vegetable colouring matter, and also of the colouring matter of decayed wood. Nor is this all, for, in another communication-for these things are now beginning to crowd upon us, and they will continue to do so much more by-and-by-Dr. Phipson asserts that this new method is perfectly competent to indicate any ar.i- 
ficial coloration of wine. Mir. Sorby, on the other hand, has given his attention to beer; so that you see, if I have been taking you occasionally to the stars, I sometimes have the opportunity of travelling a great deal nearer home.

MIr. Sorby has also made some extremely delicate and interesting researches on the colouring matters existing in leaves. He has been able to identify numerous colouring principles, which he has arranged in five distinct groups: these groups rejoice in the names of chlorophyll, xantophyll, erythrophyll, chrysophyll, and phaiophyll, the absorption spectra of which are perfectly distinct and well marked. It is found generally that leaves contain colours belonging to several groups, and frequently more than one of the same group. MIr. Sorby also finds that the change of colour which takes place in autumn consists chicfly in the disappearance of the chlorophyll, which renders the remaining colours visible, and these most frequently are of a yellowish tint. Some leaves, however, turn red in the autumn : this appears to be due to a falling off of the vital power of the plant, for by artificially diminishing the vital power, the intensity of this red colour is increased.

One great value of this method of research is that it enables us to recognise special colouring-matters, even when mixed with several others, and to determine the particular conditions in which they occur in plants or animals-whether in a solid state or in solution - and whether those dissolved out by reagents exist as such in the living organisms, or are the products of decompositions.

So that you see, on the whole, at the present moment, I think we may be full of hope that the new process may gradually lead to many more practical applications; but really we cannot say much about them at present, because the introduction of spectrum analysis is so recent. We are, however, already furnished with another instance of the close connection there always must be between any great advance in physical inquiry and the application of the skill of our opticians to aid us in the inquiry. We have the Sorby-Browning spectrum microscope, and then a large number of people can study the beautiful phenomena which this new method of research has opened up to us, where formerly it was almost impossible to imagine that science, or even the practical affairs of earth, should in any way benefit.

Having thus dealt very briefly with some of the more practical applications of the subject, I must now take you a somewhat distant journey to the sun and to the stars; and I must, in the first instance, attempt to connect the two perfectly distinct classes of phenomena which I have brought to your notice, - the phenomena, namely, of radiation, and the phenomena of absorption; and this con

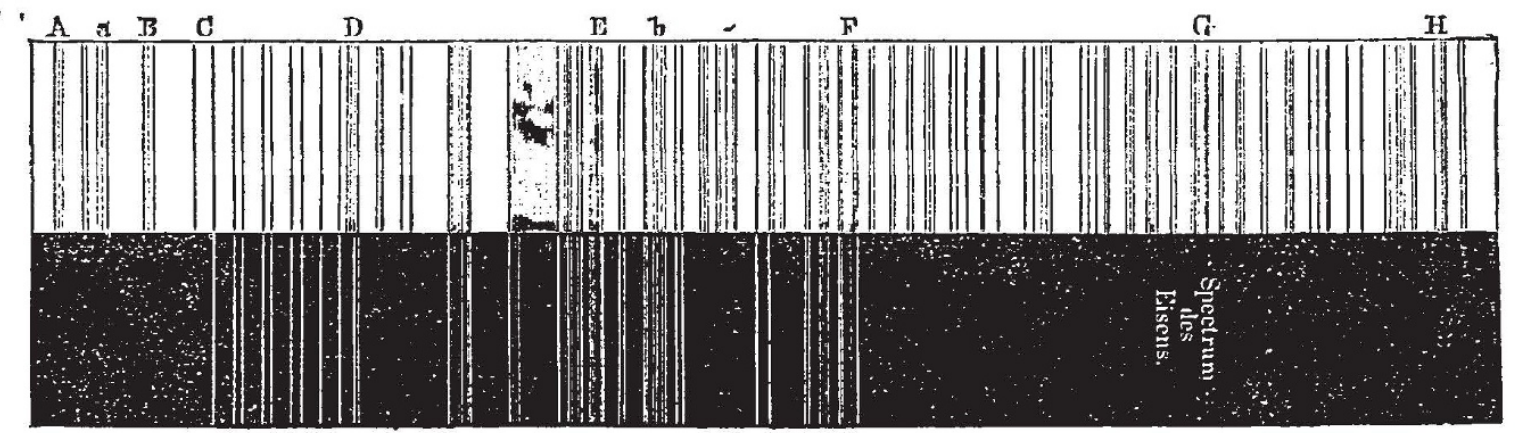

FIG. 49-Correspondence of some of the lines given out by iron vapour (below), and of some of the Fraunhofer lines in the solar spectrum.

nection between radiation land absorption is an instance of the slow growth of science. I remarked to you in the former lecture, that Fraunhofer, at the beginning of this century, had a very shrewd suspicion of the perfect co. incidence of place in the spectrum betiveen certain dark lines which he saw in the spectrum of the sun, which I promised to explain to you on this occasion, and the bright lines in the spectrum of sodium. You know how very simple the spectrum of sodium is : you will, perhaps, think it very strange indeed that such a simple thing was not explained very long ago. But Fraunhofer at the first suspected, and after him many of our greatest minds suspected, that there was some hidden, wondrously strange connection between the double yellow line which you will remember is characteristic of sodium, and a certain double line which exists among the strange black lines of the solar spectrum, which I begged you to banish from your minds on the last occasion, when we were merely dealing with radiation. But now I must ask you to bear with me while I attempt to make clear to you all the strange facts concerning these black lines. I have been favoured by Dr. Gladstone with an extract from Dr. Brewster's notebook, dated St. Andrews, October 28, 184I. In it Brewster says:- "I have this evening discovered the remarkable fact that, in the combustion of nitre upon charcoal, there are definite bright rays corresponding to the double lines of $A$ and $B$, and the group of lines $a$ in the space A B. The coincidence of two yellow rays with the two deficient ones at $\mathrm{D}$, with the existence of definite bright rays in the nitre flame, not only at $D$ but at $A, a$ and $B$, is so extra- ordinary, that it indicates some regular connection betwean the tiwo classes of phenomena." The double lines $A$ and $B$ refer to some of these dark Fraunhofer lines in the solar spectrum, which for convenience of reference were at first called after the letters of the alphabet; we no:v find that their number is so enormous that it is absolutely impossible to attempt to grapple with them in any such method, but these names are still retained.

The explanation of the coincidence between the two bright lines of burning sodium vapour and the two dark lines $D$ in the solar spectrum was first given by Prof. Stokes about $185^{2}$.

It is this. The light emitted by an incandescent vapour is due to the vibrations of its molecules, as a sound note emitted by a piano wire is due to the vibration of the wire. You have only to go into a room where there is a piano, and sing a note, to find that the wire which corresponds to your note will respond to your voice. Now, in the same way, when light is passing through a vapour, the molecules of which vibrate at any particular rate, they will be urged into their own special rate of vibrations by the vibrations of the light which correspond to that particular rate which is passing through them. Hence the light will, so to speak, be sifted, and the force it has exercised in impelling the particles in the interrupting vapour to vibrate will tell upon it ; and in this way those particular vibrations which have had the work to do will be enfeebled.

It is clear that the parts of the spectrum thus reduced in brilliancy will depend upon the vapour through which 
the light has passed. If sodium vapour be traversed, then the light corresponding to the bright lines of sodium will be enfeebled.

This great law, to which the researches of Stokes and Stewart and Angström have led, and which has been established by the experiments of Foucault, Kirchhoff, and Bunsen, may be summed up as follows :- Gases and vapours, when relatively cool, absorb those ray's zuhich they themselves emit when incandescent; the absorption is continuous or selective as the radiation is continuous or selective.

\section{(To be continued.)} J. NORMIAN LOCKYER

\section{NOTES}

Tine Emperor of Brazil has conferred upon Dr. Warren De La Rue the distinction of Knight of the Imperial Order of the Rose.

THE subject of Professor Tait's Rede Lecture, to be delivered on the 23 rd inst., will be "Thermo-Electricity."

A PARAGRAPI has recently appeared in several scientific papers quoted from the Zeitschrift fiir Parcosilenkunde, stating that Prof. Hallier of Jena has described a new potato-disease, which made its appearance last autumn in the neighbourhood of that town, the disease being indicated by the presence of a purple web and the appearance of a number of black spots on the skin, referable apparently to the perithecia of a pyrenomycetous fungus. We learn from the Rev. M. J. Berkeley that this so-called new disease is nothing but the well-known " copper-web" which is in some years very destructive to asparagus, mint, and other crops, and has been known in some instances to attack the potato. The description in the Zeitsch ift is identical with this familiar parasite. Figures will be found in Tulasne's "Fungi Hypogæi," under Rhizoctonia, showing that the so-called perithecia are spurious. Mr. Broome has detected the form of fructification known as conidia.

LADY Lyf.l, wife of Sir Charles Lyell, Bart, F.R.S., died last Thursday, in her $65^{\text {th }}$ year. Her ladyship was the eldest daughter of the late Mr. Leonard Horner, F.R.S.

During the Easter term the folloxing lectures in natural sciences will be given at Cambridge :-On Heat (I) Advancel (for the Natural Sciences Tripos), by Mr. Trotter, Trinity College, in Lecture-room No. 11, on Mondays, Wednesdays, and Fridays at 10, commencing Vednesday, April 30 (2) Elemen. tary (for Special Examination and Ist Part of Natural Sciences Tripos), on Tuesdays, Thursdays, and Saturdays at II, com. mencing Tuesday, April 29. On Chemistry, by Mr. Main, St. John's College, on Tuesdays, Thursdays, and Saturdays at I2, in St. John's College Laboratory, commencing Thursday, April 24. Instruction in Practical Chemistry will also be given. On Palocontology - the Mollusca, \&c., by Mr. Bonney, St. John's College, on Tuesdays and Thursdays, at 9 , commencing Thurs day, April 24. On Geology-(for the Natural Sciences Tripos, Stratigraphical Geology), by Mr. Bonney, St. John's College, on Mondays, Wednesdays, and Fridays, at Io, commencing Wednesday, April 23. Elementary Geology (for the First part of the Tripos and the special examination), on Tuesdays and Thursdays, at II, commencing Thursday, April 24; there will be excursions, of which notice will be given from time to time. On Butany (for the Natural Sciences Tripos), by Mr. Hicks, Sidney College, on Tucsdays, Thursdays, and Saturdays, at II, in Lecture-room No. I, beginning on Tuesday, April 29; the lectures during this term will be chiefly on Cryptogamic Botany and on Classification. Biology : the Trinity Prelector will give a course of Practical Lectures on Elementary Biology, on Mondays, Tuesdays, and Wednesdays, at II A.M., commenc- ing Wednesday, April $3^{\circ}$. This course is intended as an introduction to the study of both anatomy and physiology. A short lecture of about half-an.hour will be given at each meeting, followed by practical work for about 11 or 2 hours.

Tie annual soirdi of the Royal Society last Saturday at Burlington House was a great success. The number of visitors was exceedingly large, and the objects exhibited were numerous and varied. In the Mathematical Room, Mr. Latimer Clark showed his remarkable experiment of the influence of light on the conductivity of selenium, recently described in NATURE.

Tre office of "Lord Rector" of. a Scotch University is generally regarded as merely honorary, a testimony of the estimation in which the students hold the gentleman whom they elect. $\Lambda$ s a rule the Lord Rector acquiesces in this opinion, and seldom does more in return for the supposed honour conferred than mark the commencement or close of his three years' tenure of office by making a speech to the students. As might be surmised, Prof. Huxley, who was recently elected to the Lord Rectorship of Aberdeen University, which counts Prof. Bain among its staff of teachers, does not regard the office as merely honorary : he intends to take advantage of the position conferrred upon him by doing some actual work for the good of the University. Naturally one of the first grievances he has attacked is the medical curriculum, which at Aberdeen, as at most other medical schools, is hampered by the "traditions of the elders" as to the supposed advantages of the dead languages to a medical s'udent. Shortly after Prof. Huxley's election, he received a numerously signed petition from the medical students requesting him to use his influence to obtain the omisssion of Greek as a compulsory subject in the preliminary examination. Prof. Iuxley has given notice that he will bring forward at the next meeting of the University Court a resolution to reform the medical curriculum at Aberdeen, as he considers it at prèsent rather overweighted with classics, and believes that some new arrangement would probably be exceedingly advantagcous, especially in the matters of natural history and botany.

WE hear from Mr. Lloyd that living specimens of the Lancelet (Amplioxus la nccolatus) have been very recently received at the Crystal Palace Aquarium; from Naples, and are now alive. We hope that Dr. Dohrn will be successful in sending other living specimens of this most interesting fish to other Aquaria in this country, so that its affinities and development may be more thoroughly worked out and generally understood.

Mr. Thomas William Bridge was on Friday elected to a Natural Science Scholarship at Trinity College, Cambridge. Mr. Bridge has for some two years worked under Mr. J. W. Clark, the Superintendent of the University Museums of Zoology and Comparative Anatomy, and about a month since was appointed, by the Professor of Zoolory, to the newly-founded post of Demonstrator in Comparative Anatomy in the University.

Dr. DIVERs, of the Middlesex Hospital, has been appointed to the Professorship of Chemistry in the new Engineering College at Jeddo.

Prof. Agassiz has not been behindland in employing the advantages placed at his disposal by Mr. Anderson's munificent becuest. A programme is already published of a summer course of Natural History at Penekese Island, designed chiefly for teachers, and for students preparing to become teachers. Among those that Prof. Agrasiz is able to include on his staff we find the names of Profs. Shaler, Wilder, Packard, and Putnam, and every attempt is being made to obtain a sufficient endowment, through the liberality of others, to offer the course free of charge to deserving students. The Superintendent of the United States Cosst Survey and the United States Commissioner of Fisheries have also promised all the assistance in their power to this excellent undertaking. 